\title{
ANTROPOFAGIA E PARANGOLÉ NA TERRA DE MAKUNAIMA: VIVENDO E COMPARTILHANDO EXPERIÊNCIAS PLURAIS
}

\author{
ANTHROPOPHAGY AND PARANGOLÉ IN THE LAND OF MAKUNAIMA: \\ LIVING AND SHARING PLURAL EXPERIENCES
}

\author{
ANTROPOFAGIA Y PARANGOLÉ EN LA TIERRA DE MAKUNAIMA: \\ VIVIR Y COMPARTIR EXPERIENCIAS PLURALES
}

Ivete Souza da Silva ${ }^{1}$

\begin{abstract}
Resumo: Antropofagia e parangolé na terra de Makunaima é uma proposição educativa que fez parte do V Festival Internacional de Teatro e Artes Performáticas (V FITAP), proposta pelo Grupo de Estudo e Pesquisa Cruviana: Educação, Arte e Intercultura. Realizada no Espaço Cultural "Casa do Neuber" localizado na cidade de Boa Vista, Estado de Roraima. A proposição faz referência a Antropofagia Cultural Brasileira ocorrida no Brasil na década de 1920, a série de obras Parangolé do artista plástico e performático Hélio Oiticica e ao Estado de Roraima na figura de Makunaima personagem da lenda indígena do povo Makuxi. Durante a proposição o público vivenciou uma experiência artística performática onde artistas convidados expuseram seus trabalhos e produziram junto com o público. A vivência provocou a construção de um outro espaço educativo onde a aprendizagem se deu a partir de espaços de compartilhamento e criação, movimentados pelos saberes, fazeres, memórias e afetos de cada pessoa lá presente. Malabaristicamente, apresentamos um canto dos nortes aos Brasis e um canto dos Brasis ao mundo, levando um pouco da educação e da arte que teimosamente fazemos.
\end{abstract}

Palavras-chave: Antropofagia; parangolé; Makunaima.

\begin{abstract}
Anthropophagy and parangolé in the land of Makunaima is an educational proposition that was part of the V International Festival of Theater and Performing Arts (V FITAP), proposed by the Cruvian Study and Research Group: Education, Art and Interculture. Held at the "Casa do Neuber" Cultural Space located in the city of Boa Vista, State of Roraima. The proposition makes reference to Brazilian Cultural Antropofagia that took place in Brazil in the 1920s, the series of works Parangolé by the plastic and performance artist Hélio Oiticica, and the State of Roraima in the figure of Makunaima, a character in the indigenous legend of the Makuxi people. During the proposition, the audience experienced a performance artistic experience where guest artists exhibited their work and produced together with the audience. The experience led to the construction of another educational space where learning took place from spaces of sharing and creation, moved by the knowledge, actions, memories and affections of each person present there. We present a corner of the North to Brazil and a corner of Brazil to the world, taking some of the education and art that we stubbornly do.
\end{abstract}

Keywords: Anthropophagy; parangolé; Makunaima.

Resumen: Antropofagia y parangolé en la tierra de Makunaima es una propuesta educativa que formó parte del V Festival Internacional de Teatro y Artes Escénicas (V FITAP), propuesto por el Grupo de Estudio e Investigación Cruviana: Educación, Arte e Intercultura. Realizado en el Espacio Cultural "Casa do Neuber" ubicado en la ciudad de Boa Vista, Estado de Roraima. La propuesta hace referencia a la Antropofagia Cultural Brasileña que tuvo lugar en Brasil en la

\footnotetext{
${ }^{1}$ Universidade Federal de Roraima.
} 
década de 1920, la serie de obras Parangolé del artista plástico y performance Hélio Oiticica, y el Estado de Roraima en la figura de Makunaima, personaje de la leyenda indígena makuxi. Durante la propuesta, la audiencia experimentó una experiencia artística de performance donde los artistas invitados exhibieron su trabajo y produjeron junto con la audiencia. La experiencia desembocó en la construcción de otro espacio educativo donde el aprendizaje se dio desde espacios de compartir y creación, movidos por los conocimientos, acciones, recuerdos y afectos de cada persona allí presente. Presentamos un rincón del norte a Brasil y un rincón de Brasil al mundo, llevando algo de la educación y el arte que obstinadamente hacemos.

Palabras clave: Antropofagia; parangolé; Makunaima.

\section{Muito prazer, eu sou o cio da tribo}

No dia 17 de maio de 2018, no espaço "Casa do Neuber", na cidade de Boa Vista, estado de Roraima acontece a noite da Antropofagia e Parangolé na terra de Makunaima. Uma proposição educativa desenvolvida pelo Grupo de Pesquisa CRUVIANA: Educação, Arte e Intercultura, para compor a programação do $V$ Festival Internacional de Teatro e Artes Performáticas (V FITAP). Tendo como organização geral a Universidade de Trás-os-Montes em Portugal (UTAD), o V FITAP propunha reunir e divulgar ações artísticas desenvolvidas por universidades de países dos continentes da América do Sul, África e Europa promovendo um diálogo entre os países lusófonos.

Pensando em apresentar o Brasil aos estrangeiros como diria o antropófago Oswald de Andrade, e este Norte do Brasil aos brasileiros, buscamos a partir de alguns elementos constituidores das nossas culturas promover um espaço possibilitador de encontros e trocas. Para esse movimento trouxemos como referência: 1) a Antropofagia Cultural Brasileira, movimento cultural ocorrido no Brasil na década de 1920 e que tinha como um dos seus principais objetivos a construção de uma arte e cultura com raízes nacionais desenvolvida a partir da devoração do estrangeiro e sua devida apropriação, que deveria ser feita ao sabor das nossas culturas e necessidades; 2) a série de obras Parangolé do artista plástico e performático Hélio Oiticica que rompia com o conceito de público e de obra de arte, tornando-se completa apenas com a participação do corpo. O Parangolé, espécie da capa, bandeira ou estandarte, deveria ser vestido pelo "público" tornando-se uma obra única para cada um que o vestia. O movimento do corpo de cada "participante", como chamava Oiticica (2011) constituía o Parangolé de acordo com suas experiências e saberes; 3) o Estado de Roraima na figura de Makunaima personagem da lenda indígena do povo Makuxi que foi registrada pelo etnólogo alemão Theodor Koch-Grünberg e apropriada por Mario de Andrade na obra "Macunaíma: o herói sem nenhum caráter".

O espaço "Casa do Neuber", local escolhido para abrigar o encontro, também é ingrediente principal do "caldeirão cultural" (SILVA; SANTOS, 2016, p. 460) que buscamos apresentar. O espaço foi criado e mantido, durante o período de 2013 a 2019, pelo compositor, interprete e cantor regional Neuber Uchoa, um dos criadores do Movimento Cultural Roraimeira ocorrido em Roraima na década de 1980 e considerado desdobramento da Antropofagia Cultural Brasileira. Conforme Silva e Santos (2016, p. 462):

O Movimento Cultural Roraimeira acontece na década de 1980 quando o estado vive um período de intensa imigração de diferentes partes do país e, também, da Venezuela e Guiana Inglesa, recebendo principalmente imigrantes nordestinos que vêm trabalhar no garimpo de ouro, tendo estes a ilusão de melhorar significativamente as condições econômicas em que viviam, e, até mesmo de obter uma riqueza imediata. Esse momento foi marcado pela violência e a morte de muitos indígenas, pois grande parte dos garimpos eram localizados em terras indígenas. Diante deste cenário e aliado a situação de 
transformação do Território Federal de Roraima em Estado (1988), o Movimento Roraimeira, por meio de alguns artistas, dentre eles Zeca Preto, Neuber Uchoa e Eliakin Rufino, buscava em um primeiro momento, exaltar as riquezas naturais de Roraima e valorizar a forte contribuição dos povos indígenas para a formação cultural local (SILVA; SANTOS, 2016, p. 462).

Assim como o Movimento Antropofágico da década de 1920, o Movimento Roraimeira buscou nos elementos culturais da terra subsídios para pensar a sua identidade, sua arte e sua cultura. Tendo como referência os povos indígenas, os roraimeiras fizeram a sua arte. Considerados povos tradicionais do Brasil, os povos indígenas constituem um alto índice populacional no estado de Roraima que possui atualmente 11 etnias indígenas, distribuídas em 32 Terras Indígenas demarcadas, conforme dados da Fundação Nacional do Índio (FUNAI, 2021). Em suas músicas, área em que ficou mais conhecido, misturavam elementos da cultura indígena com elementos culturais dos povos que migravam para o estado e embalados pelo ritmo caribenho - influência do nosso país vizinho Venezuela - criavam o seu Parixara ${ }^{2}$. Para exemplificar, trago a seguir fragmentos da letra da música do poeta Zeca Preto, integrante e idealizador do Movimento Cultural Roraimeira, intitulada Roraimeira a qual foi instituída como Hino Cultural do Estado a partir da Lei 1007/15.

\author{
$[\ldots]$ \\ Diante do cenário de reconfiguração econômica/social/cultural, \\ Tua boca dourada, Tepequém, Suapi \\ Terra do Caracaranã, do caju, seriguela \\ Do buriti, do caxiri, Bem-Querer \\ Dos arraiais do meu Hi-fi \\ $[\ldots]$ \\ De um cruzeiro norteando as estrelas \\ Norte forte, macuxi, roraimeira \\ Da coragem, raça, força garimpeira \\ Cunhantã roceira tão faceira \\ Diamante, ouro, amo-te poeira \\ (PRETO apud OLIVEIRA; WANKLER; SOUZA, 2009, p. 29-30).
}

O Movimento Cultural Roraimeira foi um importante expoente para a construção da identidade roraimense e suas criações movimentam reflexões e apropriações em torno da cultura local. A arte produzida pelos artistas do movimento, em especial a música e a poesia, aos poucos vão adentrando nos mais diferentes espaços e instituições do estado de Roraima e assim enraizando e pulverizando o seu pertencimento cultural. Sendo um dos mais jovens estados brasileiros, instituído Estado Federado em 1988 com a Constituição da República Federativa do Brasil, Roraima vai se desenhando política/cultural/socialmente e em seus rabiscos as produções roraimeiras ganham espaço. As palavras de Eliakin Rufino, também idealizador do movimento, ao responder sobre a importância do movimento nos dias de hoje, nos ajuda a entender esse processo.

Hoje, os poemas são utilizados nas escolas, caem em concursos públicos e vestibulares. As músicas são executadas pelas orquestras do Exército, polícia, prefeitura etc. A música Roraimeira, por exemplo, que deu o nome ao movimento e é de autoria de Zeca Preto foi recentemente considerada como hino informal de

\footnotetext{
${ }^{2}$ Aqui faço uma referência a dança indígena que se denomina Parixara e que é usada para rituais festivos.
} 
Roraima. A música Makunaimando do Neuber Uchôa e Zeca Preto foi tombada como patrimônio cultural do Estado junto com meu poema Cavalo Selvagem no ano de 2008 pela Assembleia Legislativa. Dessa forma, nós construímos uma referência para o povo daqui. A importância é essa, ter ajudado a construir o conjunto das identidades culturais de Roraima (RUFINO, 2016, [n. p.]).

Embora a sua criação tenha se dado nos anos de 1980, o Movimento Cultural Roraimeira ainda respira e re-existe por meio das produções de alguns dos artistas que o idealizaram, como por exemplo: Neuber Uchoa, Zeca Preto e Eliakin Rufino. Em suas produções e criações solos o "Trio Roraimera", como era conhecido, mantém vivo os princípios que deram origem ao movimento e individualmente seguem o seu trabalho de fomento a cultura e identidade plural roraimense. E nesse contexto se insere a "Casa do Neuber", espaço que acolhia as Artes produzidas em Roraima (em especial a música e as artes visuais), que eram apresentadas ao sabor de uma damurida, feita pelo próprio Neuber Uchoa. A damurida, iguaria indígena feita de peixe ou carne de caça que tem como base a pimenta e o tucupi, era uma das estrelas das noites de quinta-feira, dia em que a "Casa do Neuber" abria suas portas para receber os roraimenses e roraimados ${ }^{3}$ e apresentar as suas Artes.

E foi em uma noite de quinta-feira que vivenciamos Antropofagia e Parangolé na terra de Makunaima, levando um pouco da educação e da arte que teimosamente fazemos. Inventamos a nossa noite do Brasil com irreverências mil, que ficaram gravadas não apenas em nossos corpos, mas, também, registradas por meio de filmagem, que possibilitou a transmissão no $V$ FITAP, e que nos permite contar e mostrar essa experiência em outros espaços para aqueles que desejarem conhecer. É um pouco de antropofagia e parangolé da terra de Makunaima que oferecemos a professores(as), artistas, escritores(as), inventores(as), cientistas e andarilhos(as) que se somaram ao $22^{\circ}$ COLE. Em tempos de sombra e de dor, queremos trocar, buscar e construir espaços de sonhos e esperança.

\section{As proposições: um conceito em processo}

A ideia de proposições educativas tem início no processo de doutoramento ${ }^{4}$, onde ao buscar as contribuições antropofágicas de Paulo Freire, Augusto Boal e Hélio Oiticica para a educação e a formação de professores, fui desafiada para que enquanto pesquisadora, mergulhasse na própria radicalidade do pensamento que vinha apresentando e procurasse vivenciar corporalmente os efeitos teóricos propostos pelos pensadores e artistas escolhidos por meio de processos formativos; que poderiam ser inventados por mim. Aceita a provocação pensei em algumas experimentações e/ou intervenções, que chamei de proposições educativas e foram realizadas na universidade em que desenvolvia a pesquisa e em cursos de formação de professores. Passados alguns anos, mergulhada no contexto em que estou inserida e nos desafios que ele me apresenta, sinto necessidade de avançar nessas proposições ultrapassando os limites da universidade.

Começo então um exercício de revisita ao meu próprio pensamento e as apropriações que fiz dos autores estudados. Nesse processo retomo, de forma particular, os estudos sobre Paulo Freire e Hélio Oiticica, e suas ideias começam a ganhar novos sentidos e significados em meu fazer e para o meu fazer. Tendo como alicerce a valorização da cultura e dos saberes dos

\footnotetext{
${ }^{3}$ Termo usado para se referir aos moradores de Roraima que não nasceram no estado.

${ }^{4}$ SILVA, Ivete Souza da. Antropofagia cultural brasileira e as práticas inventivas de Hélio Oiticica, Paulo Freire e Augusto Boal: contribuições ecologistas e interculturais para a formação de professores(as). 2013. Tese (Doutorado em Educação) - Programa de Pós-Graduação em Educação, Universidade Federal de Santa Maria, 2013.
} 
sujeitos, elementos estes considerados por Paulo Freire e Hélio Oiticica como essenciais para a criação de ações educativas e artísticas, respectivamente, é que busco subsídios para a construção das proposições educativas a partir de uma perspectiva intercultural.

Quando em 2013, ainda imersa na finalização da escrita da tese, parti do Rio Grande do Sul - extremo Sul do Brasil - para Boa Vista - extremo Norte do Brasil - em busca da tão desejada carreira profissional, me deparei com um contexto completamente estranho/novo e desafiador. Me senti estrangeira em meu país. Além da adaptação climática, havia também a adaptação cultural, pois esse novo lugar apresentava um outro ritmo e uma outra forma de se relacionar. Seus dialetos e sonoridades eram estranhas aos meus ouvidos e eu, por vezes (inúmeras vezes), não compreendia o que estava sendo dito, assim como não era compreendida. Tentava me adaptar explorando o local, conhecendo pessoas ou preservando alguns hábitos da minha cultura, mas sentia dificuldade para avançar no processo. Nesse momento comecei a questionar tudo o que estava estudando/pesquisando, ou melhor, a compreensão que estava fazendo do que estava estudando/pesquisando. Logo eu que escrevia sobre a importância de se relacionar com o outro/estrangeiro/diferente, com olhos livres respeitando sua cultura/fazeres/saberes. Era como se todas as teorias que havia estudado e todas as produções intelectuais que havia publicado caíssem por terra. Não era fácil conviver com o diferente. Não era simples viver em outra cultura. Não era espontâneo o diálogo entre saberes tão distantes. Era preciso rever a compreensão teórica que estava construindo e essa experiência atua como dispositivo redirecionador, levando a um processo de pesquisa sobre as identidades do/no Norte. Inicia-se então uma trajetória de pesquisa que busca conhecer os elementos culturais locais e seus processos identitários. É em meio a essas investigações que conheço o Movimento Cultural Roraimeira.

Se a Antropofagia Cultural Brasileira pode trazer subsídios teóricos e epistemológicos para pensar a educação brasileira, o Movimento Cultural Roraimeira também pode contribuir para a educação de Roraima, e porque não dizer do Brasil, oferecendo elementos para a construção de práticas educativas contextualizadas. Para tal faz-se necessário nos dispormos a avançar no processo de investigação dessas identidades múltiplas dando a elas espaço para a conversa, para o diálogo e para a construção da cidade, da escola e da universidade.

Repensando meu pensamento a partir das provocações que a vivência em um dos Nortes brasileiro trouxe, me desafio a reinventar as proposições educativas um dia rascunhadas. Imersa no contexto roraimense, nos estudos sobre o Movimento Cultural Roraimera e nos processos identitários do estado, revisito a antropofagia e os autores estudados na tese e proponho uma noite de Antropofagia e Parangolé na terra de Makunaima.

Essa proposição, assim como as demais proposições que venho desenvolvendo, têm como base teórica a ideia de "ambientação" trazida por Hélio Oiticica em seu Programa Ambiental, onde o mesmo "propõe uma manifestação total, íntegra do artista nas suas criações, que poderiam ser proposições para a participação do espectador." (OITICICA, 2011, p. 81). O Programa Ambiental proposto por Hélio Oiticica é construído a partir do conjunto de suas obras experienciais (Os Núcleos, os Penetráveis, os Bólides e os Parangolés), e tem como uma de suas principais características a possibilidade de criação e invenção a partir da valorização das particularidades de cada espaço e indivíduo. A ideia de ambiental é para Hélio Oiticica (2011, p. 80) "[...] a reunião indivisível de todas as modalidades em posse do artista ao criar - as já conhecidas: cor, palavra, luz, ação, construção, etc., e as que a cada momento surge na ânsia inventiva do mesmo ou do próprio participador ao tomar contato com a obra". Nesse sentido,

[...] Há tal liberdade de meios, que o próprio ato de não criar já conta como uma manifestação criadora. Surge ai uma necessidade ética de outra ordem de manifestação, que incluo também dentro da ambiental, já que os seus meios 
se realizam através da palavra, escrita ou falada, e mais complexamente do discurso: é a manifestação social incluindo aí fundamentalmente uma posição ética (assim como uma política) que se resume em manifestações de comportamento individual (OITICICA, 2011, p. 81).

Da mesma forma que o Parangolé se constitui com o movimento e o formato do corpo de quem o veste, a proposição também ganha delineamentos diferentes, novos ou velhos, dependendo dos participantes que a fazem com o movimento dos seus corpos. Antropofagia e Parangolé na terra de Makunaima, não é uma proposição pronta, mas que vai sendo construída a partir das necessidades que vamos sentindo e das vozes (faladas, escritas, musicadas, dançadas) das pessoas participantes. Assim, vamos exercitando a prática de produzir conhecimento com a sociedade e não o de estender o conhecimento produzido na universidade para a sociedade.

Educar e educar-se, na prática da liberdade, não é estender algo desde a 'sede do saber' até a 'sede da ignorância' para 'salvar', com este saber, os que habitam nesta. Ao contrário, educar e educar-se, na prática da liberdade, é tarefa daqueles que sabem que pouco sabem - por isso sabem que sabem algo e podem assim chegar a saber mais - em diálogo com aqueles que, quase sempre, pensam que nada sabem, para que estes, transformando seu pensar que nada sabem em saber que pouco sabem, possam igualmente saber mais (FREIRE, 2011, p. 25).

A contribuição do pensamento freireano atravessa a reinvenção das proposições educativas pensadas por mim, na medida em que propõe um espaço de aprendizagem a ser construído pelas pessoas presentes nele. Nosso "saber" foi levado por meio da arte provocadora e aberta para sua criação junto com os "saberes" das gentes que se fizeram presente. Assim, a aprendizagem se deu a partir de espaços de compartilhamento e produção de saberes, fazeres, memórias e afetos. Malabaristicamente, apresentamos um canto dos nortes aos Brasis e um canto dos Brasis ao mundo.

\section{Antropofagia e parangolé na terra de Makunaima}

Temos que apresentar o Brasil aos estrangeiros.

Como, porém? Copiando deles e mal copiado?

Trabalharemos por um Brasil brasileiro, característico.

Oswald de Andrade (1990, p. 56)

Aceito o convite deixado por Oswald de Andrade, trabalhando por um Brasil e um Norte brasileiro e característico, nos apresentamos embalados pela música Cruviana na voz de Neuber Uchoa:

Muito prazer, estou aqui pra dizer

Que canto pra minha aldeia, sou parte da teia

Da aranha sou par

E como o rio que me banha e que te manha

É branco do mesmo trigo

Eu sou o cio da tribo

E posso até fecundar

\footnotetext{
${ }^{5}$ Os dentes do dragão: entrevistas. 2. ed. São Paulo. Globo, 1990.
} 
Meu chibé com carne seca te provoca

Minha damorida queima e te ensopa

Teu café na rede, mi capitiana

Tua tez me cruviana (UCHOA, 1992).

Quem adentrava a "Casa do Neuber", naquela noite de quinta-feira, se deparava com Macunaíma que logo na entrada recepcionava os convidados e anunciava as demais obras de arte espalhadas no ambiente. Nas mesas os participantes eram provocados a ler e/ou a bordar enquanto tomavam a sua damurida e conversavam entre si. Ao centro da casa, próximo ao palco onde Neuber nos apresentava, a antropofagia em macunaíma era anunciada performativamente. Nas mesas, misturados ao público, artistas ${ }^{6}$ produziam seus trabalhos e provocavam experiências em e com Arte.

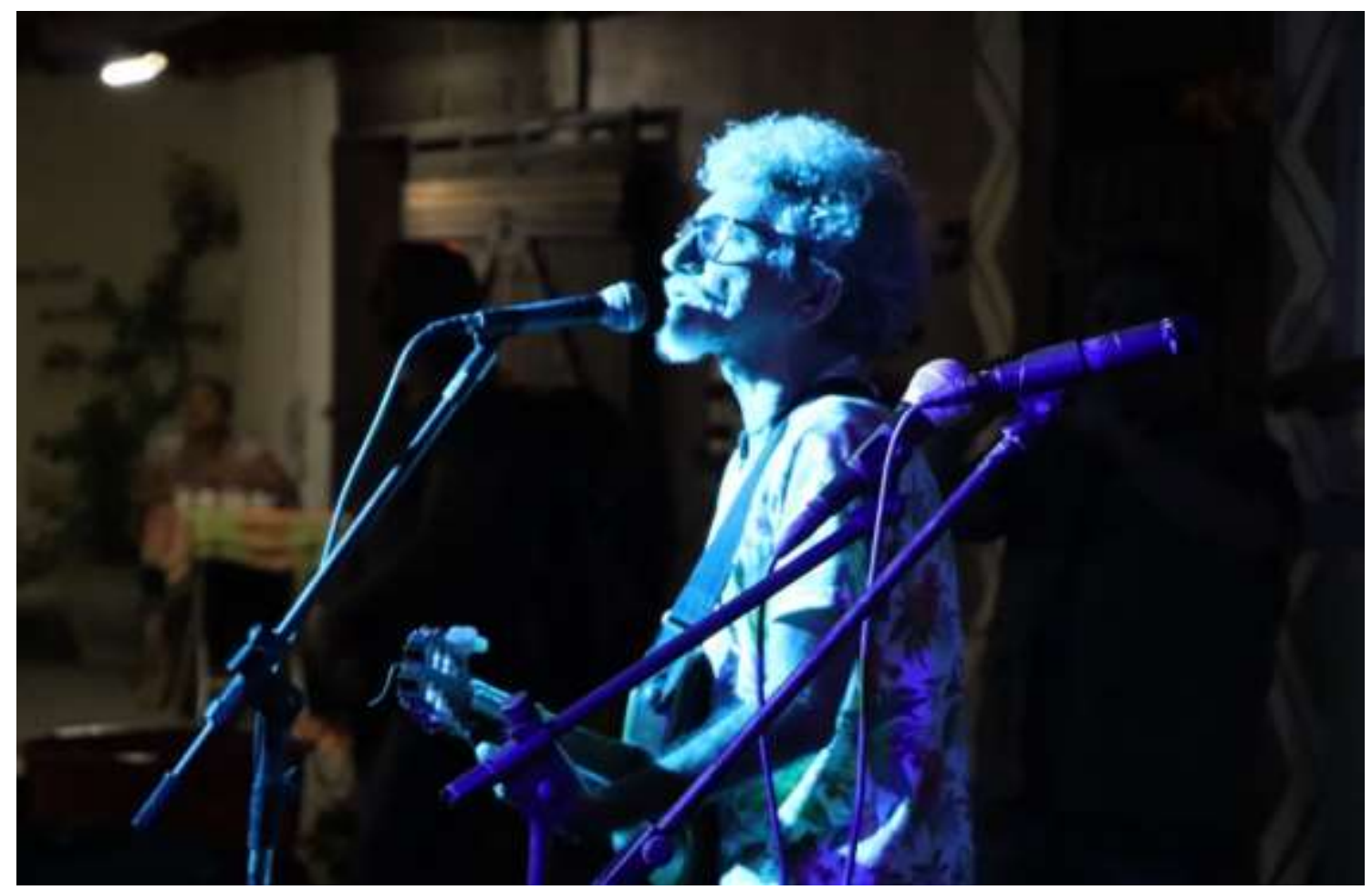

Figura 1: Neuber Uchoa - Fonte: Arquivo pessoal da pesquisadora - Fotografia: Lisiane Aguiar

\footnotetext{
${ }^{6}$ Participaram da ação artística performática os seguintes artistas: Neuber Uchoa com a apresentação da música "Cruviana"; Odélia Rodrigues Medeiros com a instalação "Cantinho de Macunaíma" e sua arte em crochê; Grupo de teatro Companhia Devaneios com a performance "Antropofagia em Macunaíma"; Vinícius Luge com suas aquarelas "Água com pigmento"; Georgina Sarmento com "Ilustrações Bordadas".
} 


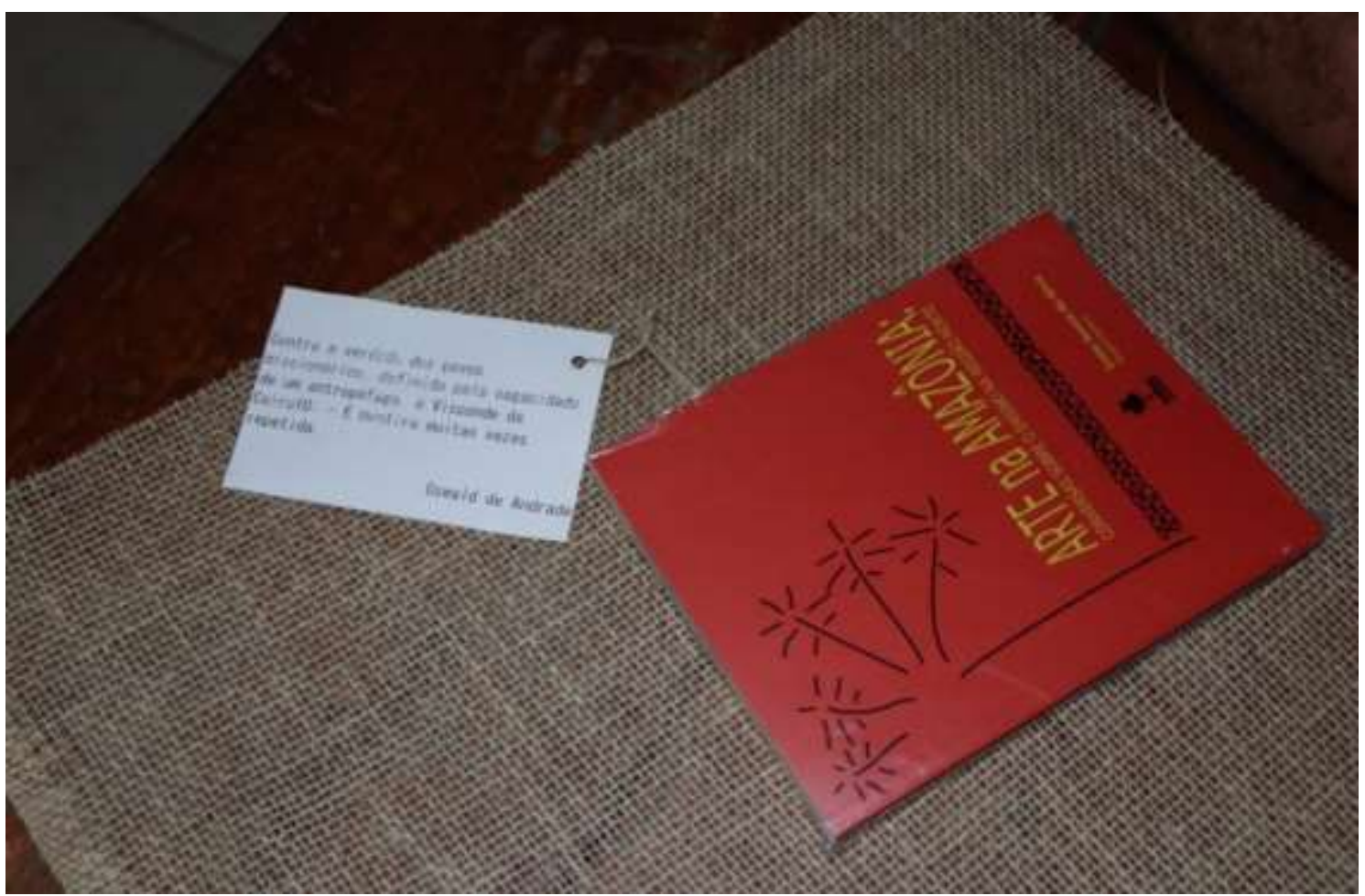

Figura 2: Mesa recebedora do público - Fonte: Arquivo pessoal da pesquisadora - Fotografia: Lisiane Aguiar

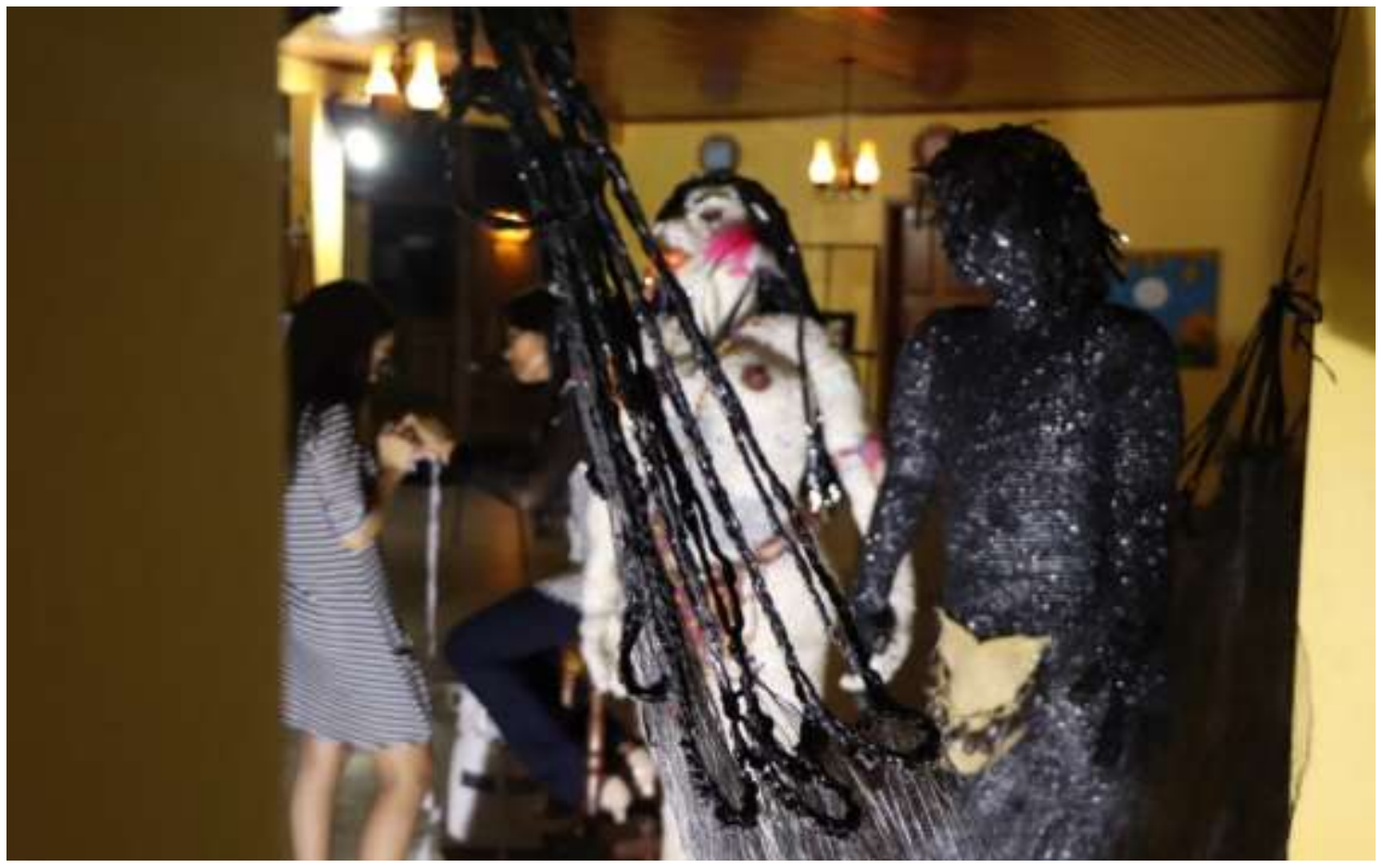

Figura 3: Cantinho de Macunaíma, Odélia Rodrigues - Fonte: Arquivo pessoal da pesquisadora - Fotografia: Lisiane Aguiar 


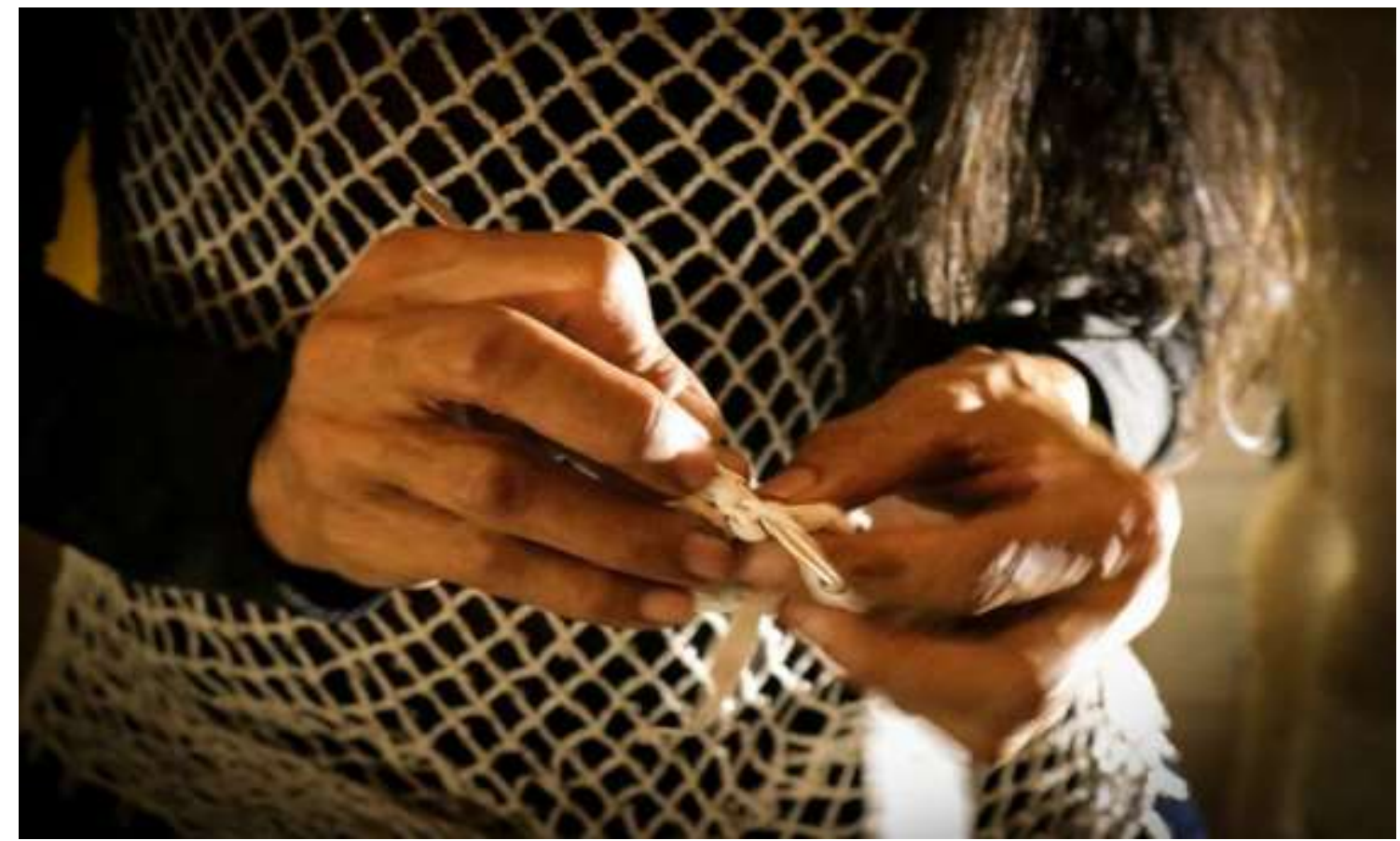

Figura 4: Odélia Rodrigues - Fonte: Arquivo pessoal da pesquisadora - Fotografia: Lisiane Aguiar

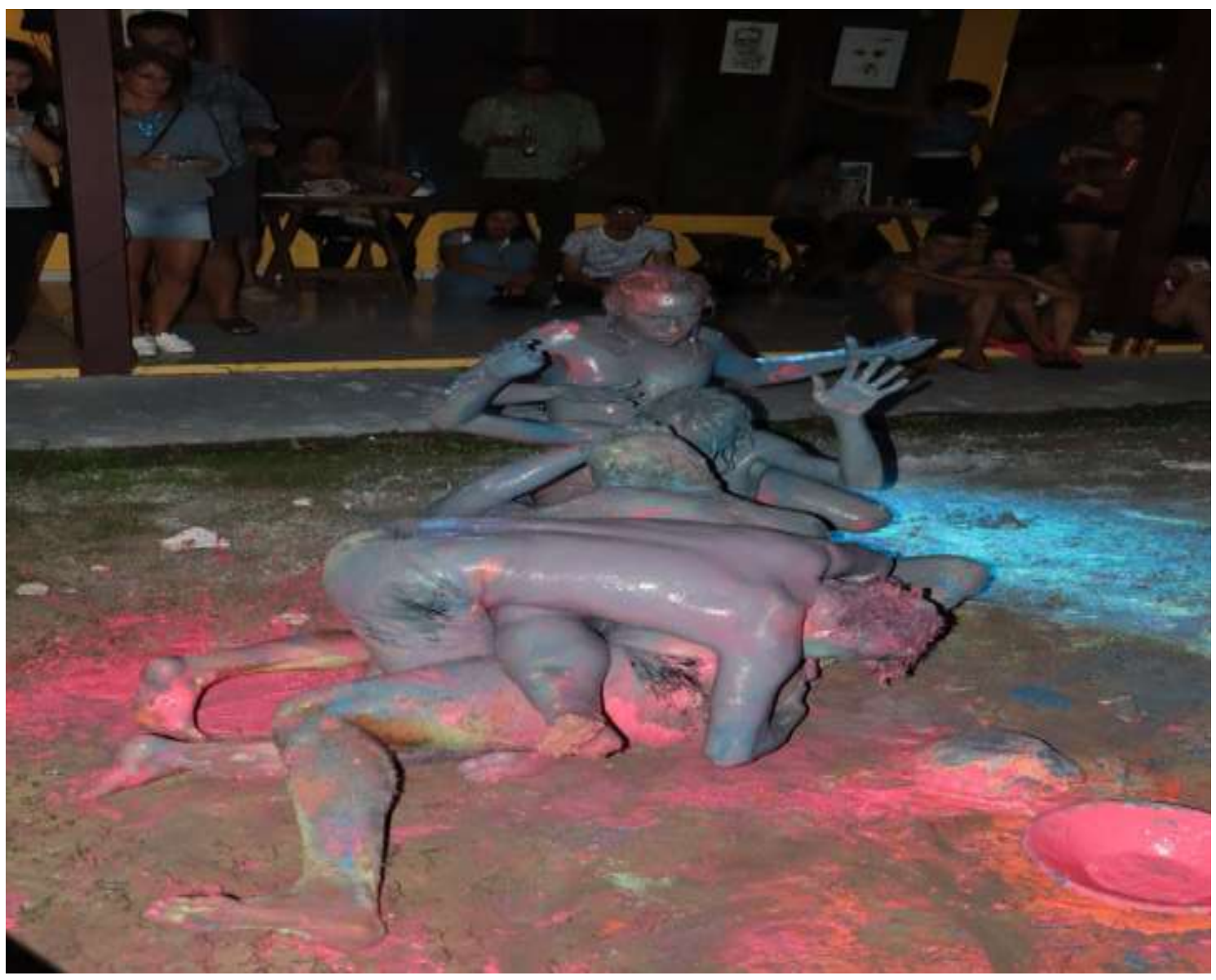

Figura 5: Companhia Devaneios, performance Antropofagia em Macunaíma Fonte: Arquivo pessoal da pesquisadora - Fotografia: Lisiane Aguiar 


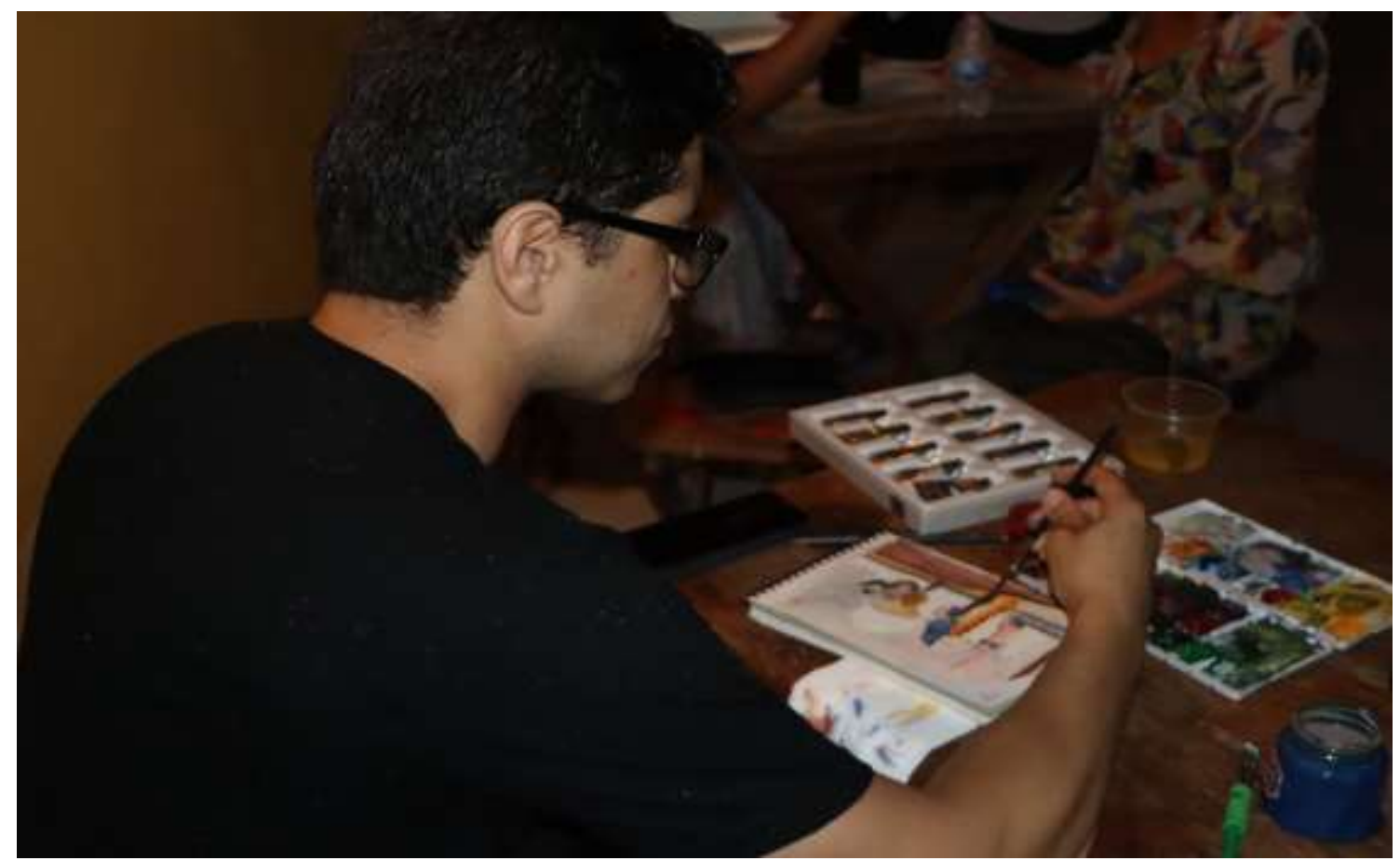

Figura 6: Artista Vinícius Luge - Fonte: Arquivo pessoal da pesquisadora - Fotografia: Lisiane Aguiar

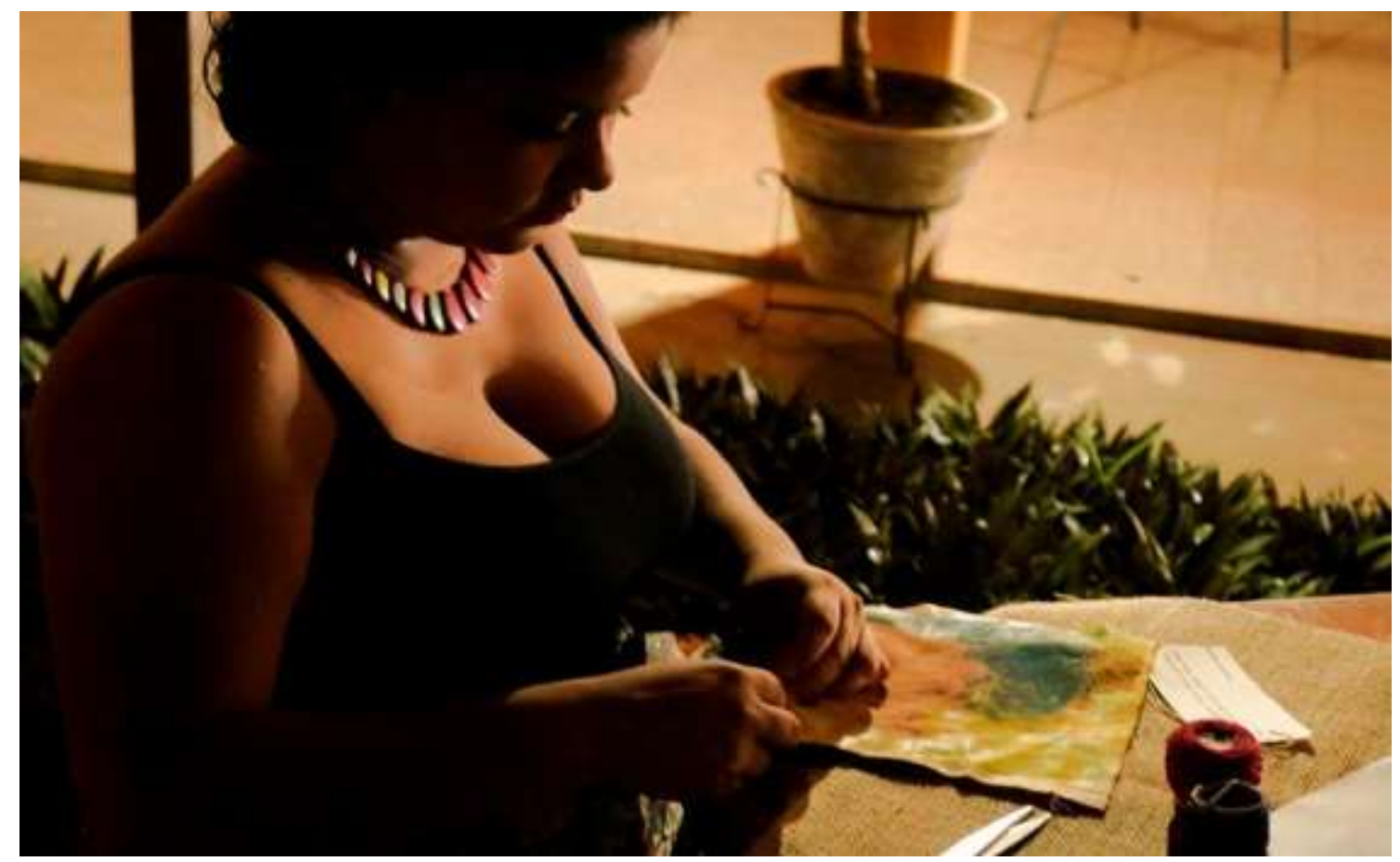

Figura 7: Artista Georgina Sarmento - Fonte: Arquivo pessoal da pesquisadora - Fotografia: Lisiane Aguiar

Sem vergonha de sermos quem somos, brasileiros/índios/brancos/negros/pardos, nos apresentamos ao mundo com nossas cores, música e corporeidade. Por meio das artes visuais e performativas apresentamos nossas histórias, nossa alegria, nossa inventividade e a capacidade devorativa de um povo que teve historicamente a possibilidade do exercício de "dialogação" negado (FREIRE, 2021). Ao sermos privados de espaços possibilitadores de diálogos também 
tivemos negado nosso direito de existir como sujeito da nossa própria história, o que nos levou a sucessivas "inexperiências democráticas enraizadas em verdadeiros complexos culturais" (FREIRE, 2021, p. 90). Nossos complexos culturais ainda não foram resolvidos, é certo. E se como afirmou Paulo Freire, ao discorrer sobre o processo de colonização no/do Brasil, a "miscigenação predisporia o brasileiro para um tipo de "democracia ética" (FREIRE, 2021, p. 101), esse certo "tipo de democracia ética" nos levou a capacidade de criação e devoração antropofágica de nós mesmos. E se "a alegria é a prova dos nove" (ANDRADE, 1928), a nossa diversidade e autenticidade é o que nos salva. E na noite de Antropofagia e Parangolé na terra de Makunaima salvamos-nos todos. Reunindo alguns dos elementos da cultura brasileira e roraimense antropofagicamente criamos possibilidades de encontros e conversas que nos permitiram olhar para gente mesmo e para as culturas e saberes que nos atravessam.

\section{Uma não-conclusão}

Assim como "todo mundo espera alguma coisa de um sábado à noite", todo mundo espera uma longa conclusão ao final de um texto. Mas este escrito não traz conclusões em um item a ser apresentado no final do texto, mas, pretendeu ir apresentando suas reflexões sobre a proposição educativa Antropofagia e Parangolé na terra de Makunaima durante o percurso da escrita. Ao contar sobre a noite de antropofagia e parangolé vivenciada na terra de Makunaima pretendeu-se também, alinhavar conclusões trazendo os atravessamentos que ela nos provocou. É certo que muito ficou em aberto, pois retomar essa experiência sempre traz novos afetos e sempre abre para outras possibilidades de reflexões. Sempre há mais o que aprofundar em sua relação com Paulo Freire e com Hélio Oiticica. Sempre ficam "fios soltos" para novas tecituras. Mas o que se pode dizer é que a proposição aqui mencionada provocou um universo de sensações e percepções naqueles que a vivenciaram e também naqueles que a assistiram através da transmissão realizada na programação do V FITAP. Antropofagia e parangolé na terra de Makunaima andarilhou pelo mundo, atravessou o oceano e rendeu conversas no além mar. Ficou registrada nas produções geradas pelo V FITAP, foi também anunciada no Boletim da FAEB (Federação de Arte Educadores do Brasil), no mês de maio daquele ano, e tem seus registros guardados no endereço: https://www.youtube.com/watch? $\mathrm{v}=\mathrm{PLrY23LtkJs \& t=6s}$ onde aqueles que desejarem espiar mais um pouco podem acessar. Muito prazer!

\section{Referências}

ANDRADE, Oswald de. Manifesto Antropófago. Revista de Antropofagia, Piratininga: ano I, n. I, 1928, p. 3.

FREIRE, Paulo. Educação como prática da liberdade. 49 ed. São Paulo: Paz e Terra, 2021.

FREIRE, Paulo. Extensão ou comunicação? 15. ed. São Paulo: Paz e Terra, 2011.

FUNAI. Terras indígenas homologadas. Disponível em: https://www.gov.br/funai/ptbr/atuacao/terras-indigenas/geoprocessamento-e-mapas. Acesso em: 14 nov. 2021.

OITICICA, Hélio. Hélio Oiticica: o museu é o mundo. In: FILHO, O. C. (Org.). Catálogo de exposições. Rio de Janeiro: Beco do Azougue, 2011. p. 01-195. 
OLIVEIRA, Rafael da Silva; WANKLER, Cátia Monteiro; SOUZA, Carla Monteiro. Identidade e poesia musicada: Panorama do movimento roraimeira a partir da cidade de Boa Vista como uma das fontes de inspiração. Revista Acta Geográfica, ano III, n. 6, jul./dez. de 2009, p. 27-37.

RORAIMA. Lei 1007/15, de 2 de agosto de 2015. Dispõe sobre o Hino Cultural do Estado de Roraima e dá outras providências. Disponível em: http://tjrr.jus.br/legislacao/index.php/leisordinarias/122-leis-ordinarias-2015/1274-lei-n-1007-de-26-de-agosto-de-2015. Acesso em: 14 nov. 2021.

RUFINO, Eliakin. Idealizador do movimento roraimeira, Eliakin dedica novo livro ao público infanto-juvenil. [Entrevista cedida a] Janaína Souza. Amazônia Real, Manaus, [n. p.], 12 abr. 2016. Disponível em: https://amazoniareal.com.br/idealizador-do-movimento-roraimeiraeliakin-dedica-novo-livro-ao-publico-infanto-juvenil/. Acesso em: 19 out. 2021.

CRUVIANA. Interprete: Neuber Uchoa. Compositor Neuber Uchoa. In: Especial de Fim de Ano Zeca Preto e Neuber Uchoa, 1972. Disponível em: https://www.youtube.com/watch?v=JAhZdKjoQvg. Acesso em: 14 nov. 2021.

SILVA, Ivete Souza da; SANTOS, Clarisse Martins dos. Movimento roraimeira: contribuições interculturais e antropofágicas ao ensino de artes no estado de Roraima. Educação, Santa Maria, v. 41, n. 2, p. 459-470, maio/ago. 2016.

\section{Sobre a autora}

Ivete Souza da Silva. Pós-Doutora em Educação (UFSC, 2020), Doutora em Educação (UFSM, 2013); Mestre em Educação (UFSM, 2010); Licenciada em Pedagogia (UFSM, 2008). Professora Adjunta na Universidade Federal de Roraima, atuando no Programa de PósGraduação em Educação e no Curso de Artes Visuais Licenciatura da instituição. Líder do grupo de Pesquisa CRUVIANA - Educação, Arte e Intercultura. Coordenadora Pedagógica do Programa de Extensão LAPECA - Laboratório de Práticas Educativas e Criação em Arte. E-mail: ivetesouzadasilva@yahoo.com.br. 